\title{
Further evidence of a cumulative effect of social disadvantage on risk of psychosis
}

\author{
S. A. Stilo ${ }^{1,2 *}$, C. Gayer-Anderson ${ }^{3}$, S. Beards ${ }^{3}$, K. Hubbard ${ }^{3}$, A. Onyejiaka ${ }^{3}$, A. Keraite ${ }^{3}$, S. Borges ${ }^{3}$, \\ V. Mondelli ${ }^{2,4}$, P. Dazzan ${ }^{1,2}$, C. Pariante ${ }^{2,4}$, M. Di Forti ${ }^{2,5}$, R. M. Murray ${ }^{1,2}$ and C. Morgan ${ }^{3,2}$ \\ ${ }^{1}$ Department of Psychosis Studies, Institute of Psychiatry, Psychology \& Neuroscience, King's College London, London, UK \\ ${ }^{2}$ National Institute for Health Research (NIHR) Mental Health Biomedical Research Centre at South London and Maudsley NHS Foundation Trust \\ and King's College London, London, UK \\ ${ }^{3}$ Department of Health Service \& Population Research, Institute of Psychiatry, Psychology \& Neuroscience, King's College London, London, UK \\ ${ }^{4}$ Department of Psychological Medicine, Institute of Psychiatry, Psychology \& Neuroscience, King's College London, London, UK \\ ${ }^{5}$ MRC Social, Genetic \& Developmental Psychiatry Centre, Institute of Psychiatry, Psychology \& Neuroscience, King's College London, London, UK
}

Background. A growing body of evidence suggests that indicators of social disadvantage are associated with an increased risk of psychosis. However, only a few studies have specifically looked at cumulative effects and long-term associations. The aims of this study are: To compare the prevalence of specific indicators of social disadvantage at, and prior to, first contact with psychiatric services in patients suffering their first episode of psychosis and in a control sample. To explore long-term associations, cumulative effects, and direction of effects.

Method. We collected information on social disadvantage from 332 patients and from 301 controls recruited from the local population in South London. Three indicators of social disadvantage in childhood and six indicators of social disadvantage in adulthood were analysed.

Results. Across all the domains considered, cases were more likely to report social disadvantage than were controls. Compared with controls, cases were approximately two times more likely to have had a parent die and approximately three times more likely to have experienced a long-term separation from one parent before the age of 17 years. Cases were also more likely than controls to report two or more indicators of adult social disadvantage, not only at first contact with psychiatric services [odds ratio (OR) 9.5], but also at onset of psychosis (OR 8.5), 1 year pre-onset (OR 4.5), and 5 years pre-onset (OR 2.9).

Conclusions. Greater numbers of indicators of current and long-term exposure are associated with progressively greater odds of psychosis. There is some evidence that social disadvantage tends to cluster and accumulate.

Received 18 April 2016; Revised 14 October 2016; Accepted 18 October 2016; First published online 5 December 2016

Key words: Causality, environment, epidemiology, reverse causation, schizophrenia, social adversity, unemployment.

\section{Introduction}

Evidence for the effects of social factors on psychosis is accumulating (Corcoran et al. 2003; Morgan et al. 2010; Howes \& Murray, 2014). Reviews of the literature suggest that being from a minority ethnic group (Boydell et al. 2001; Kirkbride et al. 2012) and having been subjected to childhood trauma (Read et al. 2005; Morgan \& Fisher 2007a; Bendall et al. 2008) are associated with an increased risk of psychosis. In addition, there is emerging evidence that specific indicators of social disadvantage are related to psychosis. Experiences of

* Address for correspondence: Dr S. A. Stilo, Psychosis Studies Department, Institute of Psychiatry, Psychology \& Neuroscience, King's College London, De Crespigny Park, SE5 8AF, London, PO Box 52, UK.

(Email: simona.stilo@kcl.ac.uk) separation or loss of a parent in childhood (Agid et al. 1999; Morgan et al. 2007b; Rubino et al. 2009; Stilo et al. 2013) as well as later social disadvantage in the form of living alone (Bechdolf et al. 2005; Drukker et al. 2006; Morgan et al. 2008; Turner et al. 2009; Ramsay et al. 2012), being single, divorced, separated (Tien \& Eaton 1992; Agerbo et al. 2004; Drukker et al. 2006; Monte et al. 2008; Morgan et al. 2008; Pelayo-Terán et al. 2008; Turner et al. 2009; Ramsay et al. 2012; ) and being unemployed (Agerbo et al. 2004; Bechdolf et al. 2005; Drukker et al. 2006; Monte et al. 2008; Morgan et al. 2008; Pelayo-Terán et al. 2008; Reininghaus et al. 2008; Turner et al. 2009; Dewa et al. 2012; Ramsay et al. 2012; Tandberg et al. 2012) are more common among those with a first-episode psychosis.

Although many studies have looked at the association between single indicators of social disadvantage

This is an Open Access article, distributed under the terms of the Creative Commons Attribution licence (http://creativecommons.org/licenses/by/4.0/), which permits unrestricted re-use, distribution, and reproduction in any medium, provided the original work is properly cited. 
and psychosis, only a few studies have specifically looked at cumulative effects and long-term associations (Agerbo et al. 2004; Morgan et al. 2008; Stilo et al. 2013).

Agerbo and colleagues, using data from three Danish population-based registers, identified a total of 5341 cases diagnosed with schizophrenia at their first admission in the period 1970-1999 and matched each individual with 10 persons of the same sex, who were born in the same year, and who were never admitted. They found that up to 15 years before admission, individuals who were not fully employed or selfemployed and those who were single, were more likely to be later admitted with schizophrenia (Agerbo et al. 2004). Morgan and colleagues, in the Aetiology and Ethnicity in Schizophrenia and Psychoses (AESOP) study, a multi-centre case-control study examining data on 390 cases and 391 controls, found that, compared with controls, cases were three times more likely to live alone, three times more likely to be single, four times more likely to be unemployed, and two times more likely to live in rented accommodation (Morgan et al. 2008). These associations were of similar magnitude and still statistically significant 1 year prior to contact with psychiatric services $(p<0.05)$ and after adjusting for age, gender, ethnicity and study centre (Morgan et al. 2008). Furthermore, in our previous study, the Genetic and Psychosis (GAP) study, social disadvantage was associated with greater risk of psychosis not only at first contact with psychiatric services[odds ratio (OR) 9.03, 95\% confidence interval (CI) 5.60-14.58] but also 1 year prior to admission (OR 5.67, 95\% CI 3.57-9.02) and 5 years prior to admission (OR 2.68, 95\% CI 1.62-4.45) (Stilo et al. 2013). None of the studies published to date have distinguished between social circumstances at onset, before onset and at first contact with psychiatric services.

Therefore, the aims of this article are: (1) To compare the prevalence of specific indicators of social disadvantage in childhood, 5 years pre-onset of psychosis, 1 year pre-onset, at onset, and at first presentation to psychiatric services, in patients suffering their first episode of psychosis, and in a control sample. (2) To explore long-term associations, cumulative effects (dose-response associations), and direction of effects.

\section{Method}

This research forms part of Childhood Adversity and Psychosis Study (CAPsy study) and the European Network of National Schizophrenia Networks studying Gene-Environment Interaction (EU-GEI study). This part is a case-control study of first episode psychosis, conducted over a 5-year period (1 May 2010 to 1 May 2015), aiming to identify the genetic, clinical and environmental factors involved in the development, severity, and outcome of psychotic disorders.

\section{Cases}

Cases were individuals with a first episode of psychosis [ICD-10: F20-29; F30-33 (psychosis codings)], aged 18-64 years, resident within a clearly defined catchment area in the south-east London boroughs of Lambeth and Southwark, who presented for the first time to specialist mental health services (population aged 18-64, approximately 332 000). The recruitment strategy was based on contacting out-patient and in-patient services regularly, interviewing staff and reviewing clinical notes, and approaching all subjects who met the inclusion criteria. To identify cases, a team of researchers regularly checked all points of potential contact with specialist mental health services in the catchment areas. All potential cases were screened for inclusion using the Screening Schedule for Psychosis (Jablensky, 1997). Each patient meeting inclusion criteria was approached and informed consent sought. 332 patients consented to participate in the study. Exclusion criteria were age $<18$ or $>64$ years, treatment with anti-psychotic medication for an episode of psychosis outside of the study period, evidence of psychotic symptoms precipitated by an organic cause, and transient psychotic symptoms resulting from acute intoxication as defined by ICD-10 (WHO, 1992).

\section{Controls}

During the same period, 301 controls were recruited, with the same inclusion and exclusion criteria as for cases, with the exception that controls had no history of a psychotic disorder. Particular attention was directed toward obtaining a control sample representative of the general population from the catchment areas by using a combination of quota and random sampling. Quota sampling segments the catchment area population (using population statistics) to determine the proportion of the local population in certain categories (e.g. gender, age, ethnicity). This is then used to set quotas for the number of controls to be recruited in each category. Two random sampling strategies were then used to identify participants to fill these quotas. First, we used the UK Postal Address File (PAF) - a list of all UK households - as a sampling frame for the catchment area (Jenkins \& Meltzer, 1995). A randomly sampled list of addresses in the boroughs of Lambeth and Southwark was generated from the PAF, and each was contacted, in person, three times (morning, afternoon, evening). All eligible adults in each household were invited to take part, and where more than one occupant was willing to participate a modified 
Kish grid was used to randomly select one member of the household. Second, we used General Practitioner (GP) lists in the catchment area as a sampling frame. Over 95\% of individuals in the UK, including inner London, are registered with a GP. We randomly selected 12 GP surgeries within the catchment area and then (via GPs) sent letters to a random sample of 400 individuals in each surgery, inviting them to participate.

Those who agreed to participate completed the Psychosis Screening Questionnaire (PSQ; Bebbington \& Nayani, 1995) and were excluded if they screened positive for a psychotic disorder or if they reported a previous diagnosis of psychotic illness.

\section{Data collection}

All subjects were interviewed with a detailed sociodemographic schedule (MRC Socio-demographic Schedule), which was amended to include items on long-term exposure to social adversities, providing information on individual and parental place of birth, individual and parental social class, migration history, ethnicity, housing and living circumstances, current and past addresses, employment history, relationships and social networks (Mallett et al. 2002; Morgan et al. 2007b); the Childhood Experiences of Care and Abuse (CECA) interview to obtain information on separation from or death of a parent/s (Bifulco et al. 1994); the Nottingham Onset Schedule to assess duration of untreated psychosis (Singh et al. 2005); the Family Interview for Genetics Studies (NIMH, 1992) to collect information on family history of psychosis (indirect measure of genetic risk). We collected clinical data using the OPCRIT (McGuffin et al. 1991), information on cannabis and use of illicit drugs using the Cannabis Experiences Questionnaire (Di Forti et al. 2009); we calculated IQ using the Satz-Mogel short form of the Wechsler Adult Intelligence Scale-revised (Satz \& Mogel, 1962) and premorbid adjustment using the Premorbid Adjustment Scale (Cannon-Spoor et al. 1982).

The variables used as indicators of social disadvantage were as follows:

Childhood disadvantage: Separation from, or death of, a parent(s) before age 17 . For the analyses, we defined long-term separation as a separation (not living in same household) from one or both parents for $\geqslant 6$ months resulting from family breakdown (parental separation or divorce, parent abandoned subject). We also focused on changes in family arrangements. Separations consequent upon planned migrations were not included (Table 1).

Adulthood disadvantage: We collected data on six social domains (living status, relationship status,
Table 1. Indicators of social disadvantage

Indicators of social disadvantage in childhood

1. Separation from, or death of, a parent(s) before age 17 Yes No

2. Changes in family arrangements before age 17 $<2$

$\geqslant 2$

Indicators of social disadvantage in adulthood

1. Living status

Live alone: alone, alone with children

Live with relatives: parents, other family

Live with others: partner/spouse, partner/spouse and children, friends, other

2. Relationship status

Single: single, divorced, widowed

In a Relationship: married, in steady relationship

3. Employment

Unemployed

Economically inactive: student, house person, retired, physical illness/disability, career

Employed: yes - full time, yes - part-time

4. Housing status

Private owned

Rented

5. Overcrowding

No

Yes

6. Monthly income

Income as median or above

Income below median

Income below official poverty

employment status, housing situation, overcrowding, monthly income) at the time of the assessment, at onset, 1 year pre-onset and 5 years pre-onset (Table 1). We distinguished between those who lived alone, those who lived with relatives, and those who lived with others, and also, between those who were single and those who were in a relationship. We distinguished between those who were employed, economically inactive and unemployed, and again, between those who were in privately owned accommodation and those who were in a rented accommodation. We defined overcrowding as presence of more persons or couples than bedrooms (separate room for: each couple, single adult aged $\geqslant 21$ years, two young people of the opposite sex aged $\geqslant 10$ years). We finally distinguished between those who were receiving a monthly income above median ( $£ 2119$ per month), at or below the UK median and those who received an income below the official poverty line ( $£ 1271$ per month). We controlled, where possible, for socio-demographic characteristics. To assess the impact of cumulative adult disadvantage, we created indices of current and 
long-term social disadvantage using, where possible, one indicator variable from each of the domains noted above (i.e. living status, relationship status, employment status, housing situation, overcrowding, monthly income).

\section{Analyses}

To test our main hypotheses, we: (1) Modelled the relationship between each form of childhood and adulthood disadvantage and risk of psychosis, taking account of potential confounding factors, using logistic regression, with case-control status as the main outcome variable. (2) Generated an index of childhood and adulthood adversity in order to assess, using logistic regression, whether the odds of psychosis (case status) increased linearly with extent of childhood and adulthood adversity. In all multivariable analyses, the following variables were controlled: age, gender, and ethnicity. In addition, we further adjusted for each of the following variables (separately, rather than simultaneously due to missing data and consequent reduction of statistical power): place of birth, subject's social class, father's social class, psychiatric family history, family history of psychosis, education, IQ, premorbid adjustment, and use of cannabis. As in previous studies, duration of untreated psychosis was defined as the period in weeks from the onset of psychosis to first contact with statutory mental health services (Singh et al. 2005; Morgan et al. 2006). Analyses were conducted using Stata v. 11 (Stata, 2009).

\section{Results}

\section{Sample characteristics}

During the study period, 561 cases were identified and approached to participate. Of these, 332 (59.2\%) provided informed consent and were included in the study. The reasons why the remaining 229 (40.8\%) did not participate included: refused consent, unable to contact again due to discharge from or nonattendance at services, and movement out of the area. We did not have information on those who did not participate and consequently cannot directly assess potential selection bias. However, we were able to compare the basic demographic and clinical characteristics of the 332 included in this study with comprehensive studies of incidence cases (Supplementary Table S1). Broadly, the characteristics of our sample are similar to other incidence samples; CAPsy study has slightly more men, the slight differences in proportions from ethnic groups may reflect demographic shifts in local population over time and/or missing data.
A total of 332 patients with a first presentation of psychosis and 301 controls agreed to participate. Of these, $63 \%$ of cases were men and $37 \%$ were women, $51 \%$ of controls were men and $49 \%$ were women. Of the cases, $77 \% \quad(n=215)$ had a diagnosis of nonaffective psychosis (schizophrenia, schizophreniform disorder, schizoaffective disorder, delusional disorder, psychosis NOS), and 23\% $(n=64)$ had a diagnosis of affective disorder (major depressive disorder with psychosis, bipolar I). Differences between cases and controls in age, gender, ethnicity, education and family history of psychosis are described in Table 2 . Differences between cases and controls in gender, ethnicity and family history of psychosis reflect wellestablished associations.

\section{Social disadvantage in childhood}

Six per cent $(n=20)$ of patients had experienced loss of a parent due to death before the age of 17 , and $6 \%(n=$ 18) had experienced separation longer than 6 months. Compared to controls, cases were approximately two times more likely to have had a parent die before the age of 17 (OR 1.95, 95\% CI 0.98-3.88), and approximately three times more likely to have experienced a long-term separation from one or both parents before the age of 17 (OR 3.04, 95\% CI 2.12-4.35) (Table 3). These findings held, with some attenuation, when the ORs were adjusted for age, gender, and ethnicity (Table 3). When we further adjusted (in turn and separately) for other potential confounders such as place of birth, subject's social class (main occupation), father's social class (occupation at birth and lifetime main occupation), education, psychiatric family history, psychosis family history, cannabis use, IQ, premorbid adjustment, the findings held with minimal attenuation (Supplementary Table S2). We also looked at family arrangements, mother and father figures that the subject lived with, for at least 1 year before the age of 17 (e.g. natural mother/father, stepmother/stepfather, etc.), and found that cases were 2.32 times (95\% CI 1.66-3.25) more likely than controls to have had $\geqslant 2$ family arrangements before age 17 (Table 3).

\section{Social disadvantage in adulthood}

Across all the domains considered, cases were more likely to report social disadvantage than controls. In particular, at first presentation to psychiatric services, compared with controls, cases were five times $(95 \%$ CI 3.39-8.21) more likely to live alone, five times (95\% CI 3.66-7.89) more likely to be single, 12 times (95\% CI 7.13-20.35) more likely to be unemployed, three times (95\% CI 2.39-5.47) more likely to live in rented accommodation, two times (95\% CI 1.31-3.25) more likely to live in overcrowded conditions, and 
Table 2. Basic socio-demographic characteristics by case-control status

\begin{tabular}{|c|c|c|c|c|c|}
\hline & Controls $(n=301)$ & Cases $(n=332)$ & $\chi^{2} / t$ & $\mathrm{df}$ & $p$ \\
\hline \multicolumn{6}{|l|}{ Age (years) ${ }^{\mathrm{a}}$} \\
\hline Mean (S.D.) & $35(12.32)$ & $28(8.67)$ & $t=7.43$ & 46 & $<0.001$ \\
\hline \multicolumn{6}{|l|}{ Gender $^{\mathrm{a}}, n(\%)$} \\
\hline Male & $153(50.83)$ & $193(62.87)$ & \multirow[t]{2}{*}{$\chi^{2}=8.97$} & \multirow[t]{2}{*}{1} & \multirow[t]{2}{*}{0.003} \\
\hline Female & $148(49.17)$ & $114(37.13)$ & & & \\
\hline \multicolumn{6}{|l|}{ Ethnicity $^{\mathrm{a}}, n(\%)$} \\
\hline White British & $131(43.52)$ & $81(26.38)$ & \multirow[t]{6}{*}{$\chi^{2}=25.51$} & \multirow[t]{6}{*}{5} & \multirow[t]{6}{*}{$<0.001$} \\
\hline Asian & $15(4.98)$ & $13(4.23)$ & & & \\
\hline Black Caribbean & $44(14.62)$ & $53(17.26)$ & & & \\
\hline Black African & $49(16.28)$ & $81(26.38)$ & & & \\
\hline Others & $24(7.97)$ & $42(13.68)$ & & & \\
\hline Non British white & $38(12.62)$ & $37(12.05)$ & & & \\
\hline \multicolumn{6}{|l|}{ Education $^{\mathrm{b}}, n(\%)$} \\
\hline No qualification & $5(1.67)$ & $53(17.55)$ & \multirow[t]{6}{*}{$\chi^{2}=122.06$} & \multirow[t]{6}{*}{5} & \multirow[t]{6}{*}{$<0.001$} \\
\hline School with qualification & $133(11.04)$ & $56(18.54)$ & & & \\
\hline Tertiary, further & $65(21.74)$ & $52(17.22)$ & & & \\
\hline Vocational & $31(10.37)$ & $80(26.49)$ & & & \\
\hline Higher (undergraduate) & $105(35.12)$ & $50(16.56)$ & & & \\
\hline Higher (postgraduate) & $60(20.07)$ & $11(3.64)$ & & & \\
\hline \multicolumn{6}{|l|}{ Place of birth ${ }^{\mathrm{a}}, n(\%)$} \\
\hline UK born & $196(65.12)$ & $174(56.68)$ & \multirow[t]{2}{*}{$\chi^{2}=4.54$} & \multirow[t]{2}{*}{1} & \multirow[t]{2}{*}{0.03} \\
\hline Non-UK born & $105(34.88)$ & $133(43.32)$ & & & \\
\hline \multicolumn{6}{|c|}{ Psychiatric family history $^{\mathrm{c}}, n(\%)$} \\
\hline No & $164(61.65)$ & $110(52.13)$ & \multirow[t]{2}{*}{$\chi^{2}=4.36$} & \multirow[t]{2}{*}{1} & \multirow[t]{2}{*}{0.03} \\
\hline Yes & $102(38.35)$ & $101(47.87)$ & & & \\
\hline \multicolumn{6}{|c|}{ Psychosis family history $^{\mathrm{d}}, n(\%)$} \\
\hline No & $252(95.45)$ & $168(84.00)$ & \multirow[t]{2}{*}{$\chi^{2}=17.39$} & \multirow[t]{2}{*}{1} & \multirow[t]{2}{*}{$<0.001$} \\
\hline Yes & $12(4.55)$ & $32(16.00)$ & & & \\
\hline
\end{tabular}

S.D., Standard deviation; df, degrees of freedom.

Missing values: ${ }^{\mathrm{a}} 25 ;{ }^{\mathrm{b}} 32 ;{ }^{\mathrm{c}} 156 ;{ }^{\mathrm{d}} 169$.

nine times (95\% CI 4.07-20.90) more likely to receive an income below the official poverty line. These associations held after account was taken of age, gender, and ethnicity. These associations were also evident in all domains at onset, 1 year pre-onset and 5 years preonset (albeit to lesser degrees) (Table 3).

\section{Cumulative impact of adult social disadvantage}

From the indicators used, we constructed indices of current and long-term social disadvantage in adult life using the following variables: unemployment, living alone, being single, living in rented house, living in overcrowding condition, receiving an income below official poverty.

We dichotomized these variables to indicate the presence or absence of an indicator, with a score of 1 for present (e.g. unemployed) and 0 for absent. This produced a potential range on the current and longterm indices (i.e. at the time of the assessment, at onset, 1 year pre-onset and 5 years pre-onset) of 0-6.
It allowed us to investigate whether the odds of psychosis increase in line with increasing disadvantage and whether cumulative effect is present. That is indeed what we found (Table 4$)$. Ninety per cent $(n=284)$ of patients, compared with $60 \%(n=184)$ of controls, reported two or more indicators of adult social disadvantage. In other words, cases were around nine times more likely than controls to report $\geqslant 2$ indicators of disadvantage at first presentation with psychosis (OR 9.50, 95\% CI 5.40-16.70) (Table 4). This association remained when we adjusted for age, gender, and ethnicity (OR 8.05, 95\% CI 4.61-14.06).

We repeated these analyses for social disadvantage at onset, 1 year pre-onset and 5 years pre-onset; at all points social disadvantage was strongly associated with later case status. Calculating the adjusted OR, cases were 7.09 (95\% CI 4.04-12.43) times more likely than controls to report social disadvantage at onset, 3.35 (95\% CI 2.13-5.27) times more likely than controls to report social disadvantage 1 year pre-onset, and 2.14 (95\% CI 1.35-3.39) times more likely than controls to 
918 S. A. Stilo et al.

Table 3. Indicators of social disadvantage by case control status

\begin{tabular}{|c|c|c|c|c|c|c|}
\hline & $\begin{array}{l}\text { Controls } \\
(n=301), n(\%)\end{array}$ & $\begin{array}{l}\text { Cases } \\
(n=332), n(\%)\end{array}$ & OR & $95 \% \mathrm{CI}$ & $\mathrm{aOR}$ & $95 \% \mathrm{CI}$ \\
\hline \multicolumn{7}{|l|}{ Childhood } \\
\hline \multicolumn{7}{|l|}{ Separation, death ${ }^{\mathrm{a}}$} \\
\hline None & $176(59.26)$ & $100(33.56)$ & 1.00 & - & 1.00 & - \\
\hline Parental death & $18(6.06)$ & $20(6.71)$ & 1.95 & $0.98-3.88$ & 1.80 & $0.87-3.73$ \\
\hline Separation & $103(34.68)$ & $178(59.73)$ & 3.04 & $2.12-4.35$ & 2.43 & $1.64-3.58$ \\
\hline \multicolumn{7}{|l|}{ Family arrangement $^{\mathrm{b}}$} \\
\hline 1 & $172(57.91)$ & $110(37.16)$ & 1 & - & 1 & - \\
\hline$\geqslant 2$ & $125(42.09)$ & $186(62.84)$ & 2.32 & $1.66-3.25$ & 1.75 & $1.21-2.55$ \\
\hline \multicolumn{7}{|l|}{5 years pre-onset } \\
\hline \multicolumn{7}{|l|}{ Living status ${ }^{c}$} \\
\hline Live with others & $152(56.30)$ & $51(24.88)$ & 1 & - & 1 & - \\
\hline Live with relatives & $50(18.52)$ & $86(41.95)$ & 5.12 & $3.07-8.54$ & 3.24 & $1.93-5.43$ \\
\hline Live alone & $68(25.19)$ & $68(33.17)$ & 2.98 & $1.84-4.81$ & 2.66 & $1.64-4.31$ \\
\hline \multicolumn{7}{|l|}{ Relationship status $^{c}$} \\
\hline In a stable relationship & $167(61.85)$ & $94(45.85)$ & 1 & - & 1 & - \\
\hline Single & $103(38.15)$ & $111(54.15)$ & 1.91 & $1.31-2.78$ & 1.56 & $1.05-2.32$ \\
\hline \multicolumn{7}{|l|}{ Employment $^{\mathrm{d}}$} \\
\hline Employed & $184(68.15)$ & $113(54.85)$ & 1 & - & 1 & - \\
\hline Economically inactive & $67(24.81)$ & 49 (23.79) & 1.19 & $0.76-1.84$ & 0.86 & $0.53-1.41$ \\
\hline Unemployed & $19(7.04)$ & $44(21.36)$ & 3.77 & $2.05-6.91$ & 3.31 & $1.77-6.20$ \\
\hline \multicolumn{7}{|l|}{ Housing status ${ }^{c}$} \\
\hline Privately owned & $98(36.30)$ & $49(23.90)$ & 1 & - & 1 & - \\
\hline Rented & $172(63.70)$ & $156(76.10)$ & 1.81 & $1.20-2.73$ & 1.32 & $0.85-2.05$ \\
\hline \multicolumn{7}{|l|}{ Overcrowding $^{\mathrm{e}}$} \\
\hline No & $219(83.59)$ & $133(70.74)$ & 1 & - & 1 & - \\
\hline Yes & $43(16.41)$ & $55(29.26)$ & 2.10 & $1.33-3.33$ & 1.51 & $0.92-2.47$ \\
\hline \multicolumn{7}{|l|}{ Monthly income ${ }^{f}$} \\
\hline As median or above & $42(16.80)$ & $8(4.97)$ & 1 & - & 1 & - \\
\hline Below median & $78(31.20)$ & $25(15.53)$ & 1.68 & $0.69-4.08$ & 1.17 & $0.46-2.92$ \\
\hline Below official poverty & $130(52.00)$ & $128(79.50)$ & 5.16 & $2.27-11.75$ & 3.16 & $1.35-7.43$ \\
\hline \multicolumn{7}{|l|}{1 year pre-onset } \\
\hline \multicolumn{7}{|l|}{ Living status ${ }^{g}$} \\
\hline Live with others & $168(55.81)$ & $78(28.89)$ & 1 & - & 1 & - \\
\hline Live with relatives & $53(17.61)$ & $92(34.07)$ & 3.73 & $2.37-5.89$ & 2.32 & $1.45-3.72$ \\
\hline Live alone & $80(26.58)$ & $100(37.04)$ & 2.69 & $1.78-4.05$ & 2.69 & $1.75-4.13$ \\
\hline \multicolumn{7}{|l|}{ Relationship status ${ }^{\mathrm{g}}$} \\
\hline In a stable relationship & $193(64.12)$ & $102(37.78)$ & 1 & - & 1 & - \\
\hline Single & $108(35.88)$ & $168(62.22)$ & 2.94 & $2.06-4.19$ & 2.62 & $1.82-3.78$ \\
\hline \multicolumn{7}{|l|}{ Employment $^{\mathrm{h}}$} \\
\hline Employed & $208(69.10)$ & $127(46.86)$ & 1 & - & 1 & - \\
\hline Economically inactive & $64(21.26)$ & $59(21.77)$ & 1.50 & $0.99-2.29$ & 1.36 & $0.86-2.14$ \\
\hline Unemployed & $29(9.63)$ & $85(31.37)$ & 4.80 & $2.90-7.93$ & 4.43 & $2.67-7.34$ \\
\hline \multicolumn{7}{|l|}{ Housing status ${ }^{\mathrm{i}}$} \\
\hline Privately owned & $116(38.54)$ & $37(13.86)$ & 1 & - & 1 & - \\
\hline Rented & $185(61.46)$ & $230(86.14)$ & 3.89 & $2.52-6.02$ & 3.11 & $1.99-4.86$ \\
\hline \multicolumn{7}{|l|}{ Overcrowding $^{j}$} \\
\hline No & $253(85.76)$ & $183(71.76)$ & 1 & - & 1 & - \\
\hline Yes & $42(14.24)$ & $72(28.24)$ & 2.37 & $1.53-3.65$ & 1.91 & $1.21-3.02$ \\
\hline \multicolumn{7}{|l|}{ Monthly income ${ }^{\mathrm{k}}$} \\
\hline As median or above & $45(15.68)$ & $10(4.44)$ & 1 & - & 1 & - \\
\hline Below median & $100(34.84)$ & $41(18.22)$ & 1.84 & $0.84-4.03$ & 1.48 & $0.65-3.34$ \\
\hline Below official poverty & $142(49.48)$ & $174(77.33)$ & 5.51 & $2.61-11.64$ & 3.77 & $1.72-8.26$ \\
\hline
\end{tabular}


Table 3 (cont.)

\begin{tabular}{|c|c|c|c|c|c|c|}
\hline & $\begin{array}{l}\text { Controls } \\
(n=301), n(\%)\end{array}$ & $\begin{array}{l}\text { Cases } \\
(n=332), n(\%)\end{array}$ & OR & $95 \%$ CI & $\mathrm{aOR}$ & $95 \%$ CI \\
\hline \multicolumn{7}{|l|}{ At onset } \\
\hline \multicolumn{7}{|l|}{ Living status ${ }^{1}$} \\
\hline Live with others & $164(54.49)$ & $64(21.99)$ & 1 & - & 1 & - \\
\hline Live with relatives & $55(18.27)$ & $90(30.93)$ & 4.19 & $1.75-5.12$ & 2.43 & $1.49-3.97$ \\
\hline Live alone & $82(27.24)$ & $137(47.08)$ & 4.28 & $2.03-5.48$ & 4.62 & $2.99-7.14$ \\
\hline \multicolumn{7}{|l|}{ Relationship status $^{\mathrm{m}}$} \\
\hline In a stable relationship & $191(63.46)$ & $83(30.51)$ & 1 & - & 1 & - \\
\hline Single & $110(36.54)$ & 189 (69.49) & 3.95 & $2.73-5.72$ & 3.74 & $2.57-5.44$ \\
\hline \multicolumn{7}{|l|}{ Employment $^{\mathrm{n}}$} \\
\hline Employed & $194(64.45)$ & $103(37.73)$ & 1 & - & 1 & - \\
\hline Economically inactive & $64(21.26)$ & $59(21.61)$ & 1.73 & $1.12-2.67$ & 1.71 & $1.06-2.74$ \\
\hline Unemployed & $43(14.29)$ & $111(40.66)$ & 4.86 & $3.08-7.66$ & 4.59 & $2.91-7.25$ \\
\hline \multicolumn{7}{|l|}{ Housing status $^{\circ}$} \\
\hline Privately owned & $116(38.54)$ & $43(15.99)$ & 1 & - & 1 & - \\
\hline Rented & $185(61.46)$ & $226(84.01)$ & 3.29 & $2.17-4.98$ & 2.61 & $1.70-4.02$ \\
\hline \multicolumn{7}{|l|}{ Overcrowding $^{p}$} \\
\hline No & $259(87.50)$ & $183(73.20)$ & 1 & - & 1 & - \\
\hline Yes & $37(12.50)$ & $67(26.80)$ & 2.56 & $1.63-4.02$ & 1.96 & $1.22-3.15$ \\
\hline \multicolumn{7}{|l|}{ Monthly income ${ }^{q}$} \\
\hline As median or above & $50(17.30)$ & $10(4.35)$ & 1 & - & 1 & - \\
\hline Below median & $92(31.83)$ & $36(15.65)$ & 1.95 & $0.88-4.30$ & 1.77 & $0.78-4.00$ \\
\hline Below official poverty & $147(50.87)$ & $184(80.00)$ & 6.25 & $2.97-13.16$ & 4.75 & $2.20-10.28$ \\
\hline \multicolumn{7}{|l|}{$\begin{array}{l}\text { At first presentation to } \\
\text { psychiatric services }\end{array}$} \\
\hline \multicolumn{7}{|l|}{ Living status ${ }^{r}$} \\
\hline Live with others & $164(54.49)$ & 56 (18.73) & 1 & - & 1 & - \\
\hline Live with relatives & $55(18.27)$ & 95 (31.77) & 5.05 & $3.10-8.22$ & 2.96 & $1.80-4.84$ \\
\hline Live alone & $82(27.24)$ & $148(49.50)$ & 5.28 & $3.39-8.21$ & 5.87 & $3.77-9.16$ \\
\hline \multicolumn{7}{|l|}{ Relationship status $^{r}$} \\
\hline In a stable relationship & $191(63.46)$ & $73(24.41)$ & 1 & - & 1 & - \\
\hline Single & $110(36.54)$ & $226(75.59)$ & 5.37 & $3.66-7.89$ & 5.31 & $3.63-7.77$ \\
\hline \multicolumn{7}{|l|}{ Employment ${ }^{\mathrm{s}}$} \\
\hline Employed & $194(64.45)$ & $64(21.19)$ & 1 & - & 1 & - \\
\hline Economically inactive & $64(21.26)$ & $67(22.19)$ & 3.17 & $2.00-5.03$ & 3.26 & $2.01-5.28$ \\
\hline Unemployed & $43(14.29)$ & $171(56.62)$ & 12.05 & $7.13-20.35$ & 11.15 & $6.99-17.80$ \\
\hline \multicolumn{7}{|l|}{ Housing status ${ }^{1}$} \\
\hline Privately owned & $116(38.54)$ & $43(14.78)$ & 1 & - & 1 & - \\
\hline Rented & $185(61.46)$ & $248(85.22)$ & 3.61 & $2.39-5.47$ & 2.86 & $1.86-4.38$ \\
\hline \multicolumn{7}{|l|}{ Overcrowding $^{t}$} \\
\hline No & $259(87.50)$ & $203(77.19)$ & 1 & - & 1 & - \\
\hline Yes & $37(12.50)$ & $60(22.81)$ & 2.06 & $1.31-3.25$ & 1.56 & $0.97-2.53$ \\
\hline \multicolumn{7}{|l|}{ Monthly income ${ }^{\mathrm{u}}$} \\
\hline As median or above & $50(17.30)$ & $8(3.20)$ & 1 & - & 1 & - \\
\hline Below median & $92(31.83)$ & $25(10.00)$ & 1.69 & $0.70-4.06$ & 1.75 & $0.71-4.30$ \\
\hline Below official poverty & $147(50.87)$ & $217(86.80)$ & 9.22 & $4.07-20.90$ & 8.35 & $3.64-19.11$ \\
\hline
\end{tabular}

OR, Odds ratio; aOR, adjusted odds ratio for: age, gender, ethnicity; $\mathrm{CI}$, confidence interval.

Missing values (full sample): ${ }^{\mathrm{a}} 38 ;{ }^{\mathrm{b}} 40 ;{ }^{\mathrm{c}} 158 ;{ }^{\mathrm{d}} 157 ;{ }^{\mathrm{e}} 183 ;{ }^{\mathrm{f}} 222 ;{ }^{\mathrm{g}} 62 ;{ }^{\mathrm{h}} 61 ;{ }^{\mathrm{i}} 65 ;{ }^{\mathrm{j}} 83 ;{ }^{\mathrm{k}} 121 ;{ }^{\mathrm{l}} 41 ;{ }^{\mathrm{m}} 60 ;{ }^{\mathrm{n}} 59 ;{ }^{\mathrm{o}} 63 ;{ }^{\mathrm{p}} 87 ;{ }^{\mathrm{q}} 114 ;{ }^{\mathrm{r}} 33 ;{ }^{\mathrm{s}} 30 ;{ }^{\mathrm{t}} 74$; ${ }^{\mathrm{u}} 94$.

report social disadvantage 5 years pre-onset (Fig. 1). The ORs were greater closest to onset suggesting that social disadvantage may not only contribute to onset but may also worsen as a consequence of developing prodromal symptoms. These results were independent of a number of potential confounders (adjusted in turn and separately): place of birth, subject's social class, father's social class, level of education, cannabis use, 
Table 4. Linear relationship and cumulative effect of social adversity by case-control status

\begin{tabular}{|c|c|c|c|c|c|c|}
\hline & $\begin{array}{l}\text { Controls }(n=301) \\
n(\%)\end{array}$ & $\begin{array}{l}\text { Cases }(n=332) \\
n(\%)\end{array}$ & OR & $95 \% \mathrm{CI}$ & $\mathrm{aOR}$ & $95 \%$ CI \\
\hline \multicolumn{7}{|c|}{ Social adversity (5 years pre-onset) ${ }^{\mathrm{a}}$} \\
\hline 0 & $39(14.44)$ & $9(4.31)$ & 1 & - & 1 & - \\
\hline 1 & $66(24.44)$ & $28(13.40)$ & 1.83 & $0.77-4.33$ & 1.11 & $0.45-2.74$ \\
\hline$\geqslant 2$ & $165(61.11)$ & $172(82.30)$ & 2.95 & $1.89-4.61$ & 2.14 & $1.35-3.39$ \\
\hline \multicolumn{7}{|c|}{ Social adversity (1 year pre-onset $)^{\mathrm{b}}$} \\
\hline 0 & $49(16.28)$ & $5(1.82)$ & 1 & - & 1 & - \\
\hline 1 & $73(24.25)$ & $31(11.31)$ & 4.16 & $1.46-11.81$ & 3.03 & $1.07-8.58$ \\
\hline$\geqslant 2$ & $179(59.47)$ & $238(86.86)$ & 4.50 & $2.89-7.00$ & 3.35 & $2.13-5.27$ \\
\hline \multicolumn{7}{|c|}{ Social adversity (at onset) ${ }^{c}$} \\
\hline 0 & $47(15.61)$ & $3(1.09)$ & 1 & - & 1 & - \\
\hline 1 & $70(23.26)$ & $16(5.82)$ & 3.58 & $0.96-13.30$ & 2.58 & $0.69-9.58$ \\
\hline$\geqslant 2$ & $184(61.13)$ & $256(93.09)$ & 8.56 & $4.88-15.03$ & 7.09 & $4.04-12.43$ \\
\hline \multicolumn{7}{|c|}{ Social adversity (at assessment) ${ }^{\mathrm{d}}$} \\
\hline 0 & $47(15.61)$ & $4(1.32)$ & 1 & - & 1 & - \\
\hline 1 & $70(23.26)$ & $15(4.95)$ & 2.51 & $0.77-8.18$ & 1.82 & $0.55-5.99$ \\
\hline$\geqslant 2$ & $184(61.13)$ & $284(93.73)$ & 9.50 & $5.40-16.70$ & 8.05 & $4.61-14.06$ \\
\hline
\end{tabular}

OR, Odds ratio; aOR, adjusted odds ratio for: age, gender, ethnicity; $\mathrm{CI}$, confidence interval. Missing values (full sample): ${ }^{\mathrm{a}} 154 ;{ }^{\mathrm{b}} 58 ;{ }^{\mathrm{c}} 57 ;{ }^{\mathrm{d}} 29$.

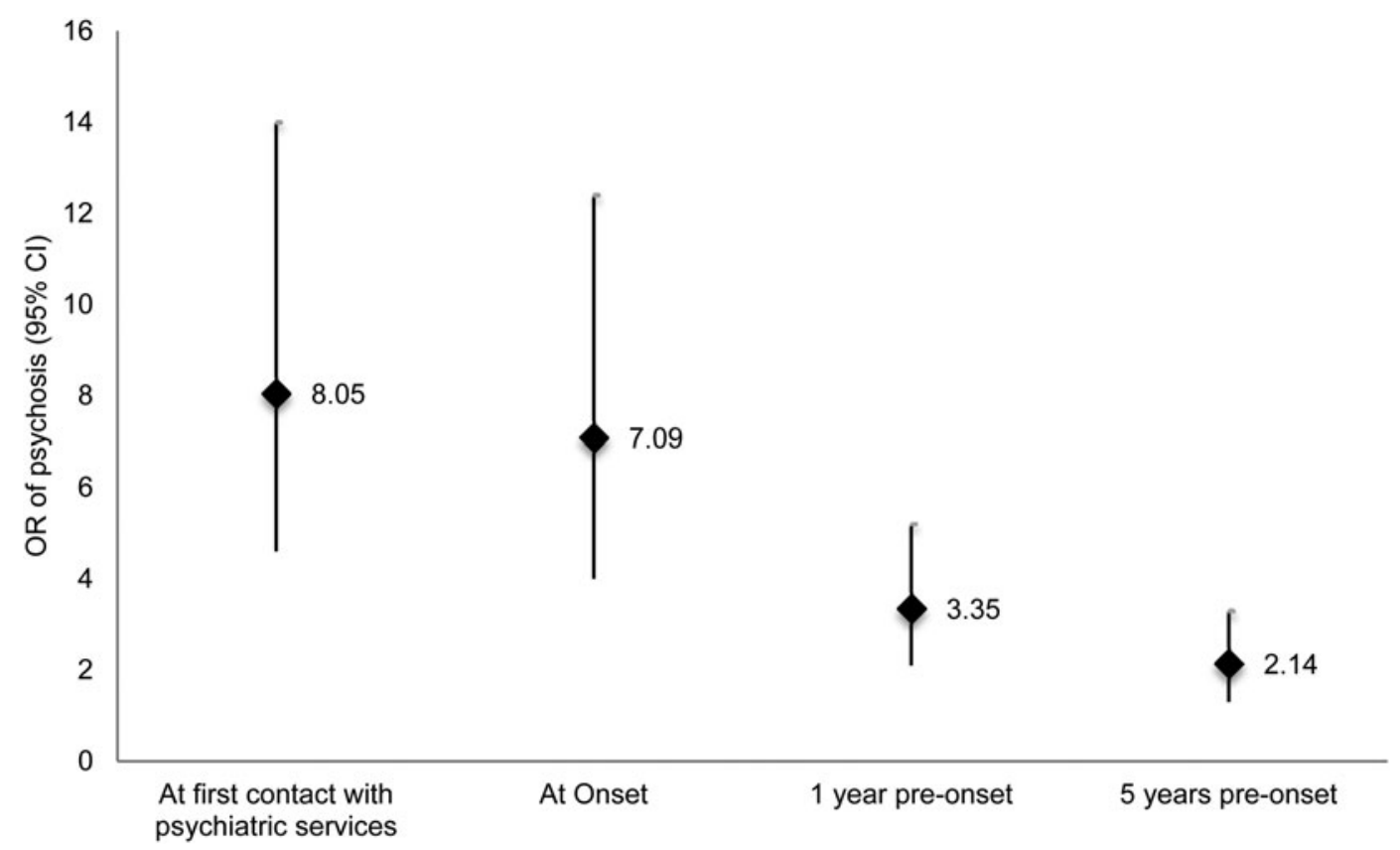

Fig. 1. Current and long term effect of cumulative social disadvantage by case-control status. OR, adjusted odds ratio (adjusted for age, gender, and ethnicity).

psychiatric family history, psychosis family history, IQ, and premorbid adjustment (Supplementary Table S3).

\section{Limitations}

Our results should be interpreted in the context of a number of limitations. First, the main issue with case- control designs is bias; cases may have been influenced by their disease experience to recall the nature or the timing of exposures differently from controls by scrutinising their memory for past exposure more intensively than controls (recall bias) and/or the investigators, believing that the exposure causes the disease, may have looked harder for the exposure in cases than 
controls (observer bias). However, living alone, being single and unemployed are contextual facts that cannot be easily forgotten and our analyses were part of a bigger study with different aims, and many researchers with primary interests unrelated to our hypotheses contributed to the collection of data. Second, although we were able to statistically adjust our results for a series of variables (place of birth, subject's social class, father's social class, level of education, childhood disadvantage, cannabis use, psychiatric family history, psychosis family history, IQ, premorbid social adjustment and premorbid academic performance), the association between social disadvantage and psychosis may be confounded by other unmeasured variables. The fact that the OR for social disadvantage in adulthood increased from 9.5 to 21 when we adjusted for IQ, from 9.5 to 26 when we adjusted for premorbid social adjustment, and from 9.5 to 15 when we adjusted for premorbid academic adjustment, is likely to be the effect of missing data; however, we cannot exclude that these variables may cover the effect of social disadvantage or may interact with social disadvantage. Third, another possible limitation is the definition of 'social disadvantage'. We considered indicators of social disadvantage in childhood as the presence of separation or loss of one or both parents before age 17 and disadvantage in adulthood as the presence living alone, being single, being unemployed, receiving a monthly income below official poverty, living in rented accommodation, and in an overcrowding condition. As shown by Wicks and colleagues in a Swedish child cohort, housing situation in childhood may be also associated with the risk of developing schizophrenia and other psychoses (Wicks et al. 2005). In addition, some of the markers we took as indicating social disadvantage (e.g. living alone) do not always indicate disadvantage while other circumstances may be considered as 'disadvantaged'; therefore the indicators included must be considered 'imperfect indicators'. Trauma and life events are without any doubt adverse social experiences and may be linked with the indicators we chose and mutually reinforcing. In addition, for a given individual, the death/separation of a parent, loss of a job, living alone, being single etc. may be considered adverse or not depending on the specific context. Finally, lack of follow-up data did not allow us to establish whether clinical outcome was associated with pre-onset cumulative social disadvantage.

\section{Discussion}

Our findings provide support for the hypothesis that social disadvantages - and the experiences they index - constitute risk factors for psychosis. Consistent with published studies (Agid et al. 1999; Morgan et al. 2007b; Rubino et al. 2009; Stilo et al. 2013), longterm separation from and death of a parent before the age of 17 were both associated with approximately a 2- to 3-fold-increased odds of psychosis independent of a number of potential confounders. When number of family arrangements was analysed, cases were more likely to report $\geqslant 2$ arrangements, a likely effect of separation. All six indicators of social disadvantage in adulthood (living alone, being single, unemployed, living in a rented accommodation, in overcrowding conditions, receiving an income below official poverty) were more prevalent in cases than controls not only at first contact with psychiatric services but also at onset, 1-year pre-onset, and 5 years pre-onset of frank psychosis. The strength of our work is the consideration of long-term associations and cumulative effects of social disadvantage, whereby a greater number of indicators of social disadvantage are associated with greater risk of psychosis. We replicated the findings from the AESOP study (Morgan et al. 2008) and the GAP study (Stilo et al. 2013) and extended them by using a wider number of indicators of social disadvantage and by looking at social disadvantage at 5 years pre-onset, at 1 year pre-onset, at onset and at first presentation to psychiatric services. In this, our results on childhood and adulthood disadvantage argue against social disadvantage being simply an epiphenomena of impending illness, which is in keeping with other studies (Hafner et al. 1999).

As in our previous results (Stilo et al. 2013) the strongest factor associated with psychosis was unemployment (OR 12.05, 95\% CI 7.13-20.35). Interestingly, by comparing our results with previous studies in England (AESOP collecting data from 1997 to 2000, GAP collecting data from 2005 to 2010 ) it is evident that the patients currently studied had been experiencing higher levels of social disadvantage compared with controls, a possible consequence of the economic recession which started towards the end of the GAP study ( 2008) and intensified during the current study. These changes over time are alarming and social policy should focus on preventing damages caused by current and past social disadvantage.

\section{Reverse causation}

Social disadvantage may be associated with psychosis either because social disadvantage causes psychosis, or because the precursors of psychosis causes social disadvantage. The problem is that causation is not directly observable; it can only be inferred (Schwartz \& Susser, 2006). We clearly cannot exclude the possibility that social disadvantage is the consequence of the illness, the consequence of trauma and life events, or that genetic factors may predispose to both social 
disadvantage and to the illness. However, our data on the duration of untreated psychosis (DUP) suggest that $79 \%(n=222)$ of patients had a DUP shorter than 1 year which argues against social disadvantage being simply an epiphenomena of impending illness. Nevertheless, social disadvantage, as described in this article, meets many of Bradford Hill's criteria for causality (Bradford Hill, 1965). In particular we were able to show a strong association between social disadvantage and psychosis (large effect size), consistency (we were able to replicate GAP and AESOP results) (Morgan et al. 2008; Stilo et al. 2013), temporality (our participants were reporting social disadvantage up to 5 years prior onset and in childhood), risk gradient (greater number of indicators were associated with greater risk), analogy (the social disadvantage-psychosis relationship was analogous to the relationship between other risk factors and psychosis). In addition, although not specifically tested in this article, there are plausible psychological and biological mechanisms that might explain the relationship. Cognitive models for psychosis suggest that pre-existing beliefs and on-going appraisals of experiences are crucial for the development and persistence of positive symptoms of psychosis (Garety et al. 2001, 2007; Freeman et al. 2002). In this context, social adversity, through negative emotional processes, might contribute to the occurrence and persistence of psychotic symptoms (Freeman et al. 2002; Garety et al. 2007; Freeman \& Garety, 2014).

In addition, evidence of dysregulation of the HPA axis in psychosis has been found in several studies. Neuroendocrinological studies of first episode, drugnaive patients with schizophrenia show evidence of basal over-activity of the pituitary-adrenal axis (Ryan et al. 2004; Walsh et al. 2005).

As suggested by van Winkel and colleagues 'behavioural sensitisation' may play an important role in how psychosocial stress, and social adversities increase the risk for psychosis (van Winkel et al. 2008).

The only criteria for causality we could not meet was 'specificity' as social disadvantage is not a specific risk factor for psychosis. However, this criterion may not be essential. In relation to physical health, for example, some risk factors are accepted as having a causal role in a number of illnesses (e.g. smoking and lung cancer, heart disease, etc.); that is, they are causal but non-specific.

\section{Future directions}

We found that our sample of cases with psychosis differed from our controls with respect to living status, marital status, work status, housing status, welfare, as well as adversity in childhood such as parental separation, and parental death. We were also able to demonstrate a cumulative effect of disadvantage and a long-term association. However, social disadvantage is only a small part of a much more complex scene.

The question remains of the mechanisms by which social disadvantage may increase risk of psychosis and how social disadvantage combines with genetic liability and other environmental risk factors. Further research will need to focus on the biologically plausible mechanisms by which genes and environment can co-influence onset of disease. Especially, we need to understand how and why genotypes and/or environment confer risk under some conditions but not under others. An interesting approach would be to examine thus, the interplay between the polygenic risk score for schizophrenia and environmental factors.

\section{Supplementary material}

The supplementary material for this article can be found at https://doi.org/10.1017/S0033291716002993.

\section{Acknowledgements}

This research has been supported by the National Institute for Health Research (NIHR) Mental Health Biomedical Research Centre at South London and Maudsley NHS Foundation Trust and King's College London. The views expressed are those of the authors and not necessarily those of the NHS, the NIHR or the Department of Health. Craig Morgan is supported by a European Research Council Consolidator Award (ERC-2014-CoG- 648837_REACH).

This research is funded by the Wellcome Trust (WT087417) and the European Union [European Community's Seventh Framework Program (grant agreement no. HEALTH-F2-2009-241909) (Project EU-GEI)].

\section{Declaration of Interest}

Professor Pariante and Dr Mondelli have received research funding from Johnson \& Johnson as part of a programme of research on depression and inflammation. In addition, Professor Pariante and Dr Mondelli have received research funding from the Medical Research Council (UK) and the Wellcome Trust for research on depression and inflammation as part of two large consortia that also include Johnson \& Johnson, GSK, Pfizer and Lundbeck. Dr Dazzan has received talk honoraria from Janssen. Professor Murray and Dr Di Forti have received honoraria for lectures supported by Janssen, Lundbeck, and Sunovian. 


\section{References}

Agerbo E, Byrne M, Eaton WW, Mortensen PB (2004). Marital and labor market status in the long run in schizophrenia. Archives of General Psychiatry 61, 28-33.

Agid O, Shapira B, Zislin J, Ritsner M, Hanin B, Murad H, Troudart T, Bloch M, Heresco-Levy U, Lerer B (1999). Environment and vulnerability to major psychiatric illness: a case control study of early parental loss in major depression, bipolar disorder and schizophrenia. Molecular Psychiatry 4, 163-172.

Bebbington PE, Nayani T (1995). The psychosis screening questionnaire. International Journal of Methods in Psychiatric Research 5, 11-19.

Bechdolf A, Pukrop R, Kohn D, Tschinkel S, Veith V, Schultze-Lutter F, Ruhrmann S, Geyer C, Pohlmann B, Klosterkötter J (2005). Subjective quality of life in subjects at risk for a first episode of psychosis: a comparison with first episode schizophrenia patients and healthy controls. Schizophrenia Research 79, 137-143.

Bendall S, Jackson HJ, Hulbert CA, McGorry PD (2008). Childhood trauma and psychotic disorders: a systematic, critical review of the evidence. Schizophrenia Bulletin 34, 568-579.

Bifulco A, Brown GW, Harris TO (1994). Childhood Experience of Care and Abuse (CECA): a retrospective interview measure. Journal of Child Psychology and Psychiatry 35, 1419-1435.

Boydell J, van Os J, McKenzie K, Allardyce J, Goel R, McCreadie RG, Murray RM (2001). Incidence of schizophrenia in ethnic minorities in London: ecological study into interactions with environment. British Medical Journal 323, 1336-1338.

Bradford Hill A (1965). The environment and disease: association or causation? Proceedings of the Royal Society of Medicine 158, 295.

Cannon-Spoor HE, Potkin SG, Wyatt RJ (1982). Measurement of premorbid adjustment in chronic schizophrenia. Schizophrenia Bulletin 8, 470-484.

Corcoran C, Walker E, Huot R, Mittal V, Tessner K, Kestler L, Malaspina D (2003). The stress cascade and schizophrenia: etiology and onset. Schizophrenia Bulletin 29, 671-692.

Dewa CS, Trojanowski L, Cheng C, Loong D (2012). Examining the factors associated with paid employment of clients enrolled in first episode of psychosis programs. Schizophrenia Research and Treatment, Vol. 2012, Article ID: 739616. doi:10.1155/2012/739616.

Di Forti M, Morgan C, Dazzan P, Pariante C, Mondelli V, Marques TR, Handley R, Luzi S, Russo M, Paparelli A, Butt A, Stilo SA, Wiffen B, Powell J, Murray RM (2009). High-potency cannabis and the risk of psychosis. The British Journal of Psychiatry 195, 488-491.

Drukker M, Krabbendam L, Driessen G, van Os J (2006). Social disadvantage and schizophrenia. A combined neighbourhood and individual-level analysis. Social Psychiatry and Psychiatric Epidemiology 41, 595-604.

Freeman D, Garety P (2014). Advances in understanding and treating persecutory delusions: a review. Social Psychiatry and Psychiatric Epidemiology 49, 1179-1189.
Freeman D, Garety PA, Kuipers E, Fowler D, Bebbington PE (2002). A cognitive model of persecutory delusions. British Journal of Clinical Psychology 41, 331-347.

Garety PA, Bebbington P, Fowler D, Freeman D, Kuipers E (2007). Implications for neurobiological research of cognitive models of psychosis: a theoretical paper. Psychological Medicine 37, 1377-1391.

Garety PA, Kuipers E, Fowler D, Freeman D, Bebbington PE (2001). A cognitive model of the positive symptoms of psychosis. Psychological Medicine 31, 189-195.

Hafner H, Loffler W, Maurer K, Hambrecht M, an der Heiden W (1999). Depression, negative symptoms, social stagnation and social decline in the early course of schizophrenia. Acta Psychiatrica Scandinavica 100, 105-118.

Howes OD, Murray RM (2014). Schizophrenia: an integrated sociodevelopmental-cognitive model. Lancet 383, 1677-1687.

Jablensky A (1997). The 100-year epidemiology of schizophrenia. Schizophrenia Research 28, 111-125.

Jenkins R, Meltzer H (1995). The national survey of psychiatric morbidity in Great Britain. Social Psychiatry and Psychiatric Epidemiology 30, 1-4.

Kirkbride JB, Errazuriz A, Croudace TJ, Morgan C, Jackson D, Boydell J, Murray RM, Jones PB (2012). Incidence of schizophrenia and other psychoses in England, 1950-2009: a systematic review and meta-analyses. PLoS ONE 7, e31660.

Mallett R, Leff J, Bhugra D, Pang D, Zhao JH (2002). Social environment, ethnicity and schizophrenia. A case-control study. Social Psychiatry and Psychiatric Epidemiology 37, 329335.

McGuffin P, Farmer A, Harvey I (1991). A polydiagnostic application of operational criteria in studies of psychotic illness. Development and reliability of the OPCRIT system. Archives of General Psychiatry 48, 764-770.

Monte RC, Goulding SM, Compton MT (2008). Premorbid functioning of patients with first-episode nonaffective psychosis: a comparison of deterioration in academic and social performance, and clinical correlates of Premorbid Adjustment Scale scores. Schizophrenia Research 104, 206 213.

Morgan C, Abdul-Al R, Lappin JM, Jones P, Fearon P, Leese $M$, Croudace T, Morgan K, Dazzan P, Craig T, Leff J, Murray R, AESOP Study Group (2006). Clinical and social determinants of duration of untreated psychosis in the AESOP first-episode psychosis study. British Journal of Psychiatry 189, 446-452.

Morgan C, Charalambides M, Hutchinson G, Murray RM (2010). Migration, ethnicity, and psychosis: toward a sociodevelopmental model. Schizophrenia Bulletin 36, 655-664.

Morgan C, Fisher H (2007a). Environment and schizophrenia: environmental factors in schizophrenia: childhood trauma a critical review. Schizophrenia Bulletin 33, 3-10.

Morgan C, Kirkbride J, Hutchinson G, Craig T, Morgan K, Dazzan P, Boydell J, Doody GA, Jones PB, Murray RM, Leff J, Fearon P (2008). Cumulative social disadvantage, ethnicity and first-episode psychosis: a case-control study. Psychological Medicine 38, 1701-1715.

Morgan C, Kirkbride J, Leff J, Craig T, Hutchinson G, McKenzie K, Morgan K, Dazzan P, Doody GA, Jones P, Murray R, Fearon P (2007b). Parental separation, loss and 
psychosis in different ethnic groups: a case-control study. Psychological Medicine 37, 495-503.

NIMH (1992). Family Interview for Genetic Studies (FIGS).

National Institute of Mental Health: Rockville, MD.

Pelayo-Terán JM, Pérez-Iglesias R, Ramírez-Bonilla $M$, González-Blanch C, Martínez-García O, Pardo-García G, Rodríguez-Sánchez JM, Roiz-Santiáñez R, Tordesillas-Gutiérrez D, Mata I, Vázquez-Barquero JL, Crespo-Facorro B (2008). Epidemiological factors associated with treated incidence of first-episode non-affective psychosis in Cantabria: insights from the Clinical Programme on Early Phases of Psychosis. Early Intervention in Psychiatry 2, 178-187.

Ramsay CE, Stewart T, Compton MT (2012). Unemployment among patients with newly diagnosed first-episode psychosis: prevalence and clinical correlates in a U.S. sample. Social Psychiatry and Psychiatric Epidemiology 47, 797-803.

Read J, van Os J, Morrison AP, Ross CA (2005). Childhood trauma, psychosis and schizophrenia: a literature review with theoretical and clinical implications. Acta Psychiatrica Scandinavica 112, 330-350.

Reininghaus UA, Morgan C, Simpson J, Dazzan P, Morgan K, Doody GA, Bhugra D, Leff J, Jones P, Murray R, Fearon P, Craig TK (2008). Unemployment, social isolation, achievement-expectation mismatch and psychosis: findings from the AESOP Study. Social Psychiatry and Psychiatric Epidemiology 43, 743-751.

Rubino IA, Nanni RC, Pozzi DM, Siracusano A (2009). Early adverse experiences in schizophrenia and unipolar depression. The Journal of Nervous and Mental Disease 197, 65-68.

Ryan MC, Sharifi N, Condren R, Thakore JH (2004). Evidence of basal pituitary-adrenal overactivity in first episode, drug naive patients with schizophrenia. Psychoneuroendocrinology 29, 1065-1070.

Satz P, Mogel S (1962). An abbreviation of the WAIS for clinical use. Journal of Clinical Psychology 18, 77-79.

Schwartz S, Susser E (2006). Detecting causes In: Psychiatric Epidemiology: Searching for the Causes of Mental Disorders (ed.
E. Susser, S. Schwartz, A. Morabia \& E. Bromet), chapter 5. Oxford University Press.

Singh SP, Cooper JE, Fisher HL, Tarrant CJ, Lloyd T, Banjo J, Corfe S, Jones P (2005). Determining the chronology and components of psychosis onset: the Nottingham Onset Schedule (NOS). Schizophrenia Research 80, 117-130.

Stata (2009). Stata Statistical Software, Release 11. College Station, TX: Stata Corporation.

Stilo SA, Di Forti M, Mondelli V, Falcone AM, Russo M, O'Connor J, Palmer E, Paparelli A, Kolliakou A, Sirianni M, Taylor H, Handley R, Dazzan P, Pariante C, Marques TR, Zoccali R, David A, Murray RM, Morgan C (2013). Social disadvantage: cause or consequence of impending psychosis? Schizophrenia Bulletin 39, 1288-1295.

Tandberg M, Ueland T, Andreassen OA, Sundet K, Melle I (2012). Factors associated with occupational and academic status in patients with first-episode psychosis with a particular focus on neurocognition. Social Psychiatry and Psychiatric Epidemiology 47, 1763-1773.

Tien AY, Eaton WW (1992). Psychopathologic precursors and sociodemographic risk factors for the schizophrenia syndrome. Archives of General Psychiatry 49, 37-46.

Turner N, Browne S, Clarke M, Gervin M, Larkin C, Waddington JL, O'Callaghan E (2009). Employment status amongst those with psychosis at first presentation. Social Psychiatry and Psychiatric Epidemiology 44, 863-869. van Winkel R, Stefanis NC, Myin-Germeys I (2008). Psychosocial stress and psychosis. A review of the neurobiological mechanisms and the evidence for gene-stress interaction. Schizophrenia Bulletin 34, 1095-1105.

Walsh P, Spelman L, Sharifi N, Thakore JH (2005). Male patients with paranoid schizophrenia have greater ACTH and cortisol secretion in response to metoclopramideinduced AVP release. Psychoneuroendocrinology 30, 431-437.

WHO (1992). International Classification of Diseases, 10th edn, (ICD-10): Classification of Mental and Behavioural Disorders. World Health Organization: Geneva.

Wicks S, Hjern A, Gunnell D, Lewis G, Dalman C (2005). Social adversity in childhood and the risk of developing psychosis: a national cohort study. American Journal of Psychiatry 162, 1652-1657. 